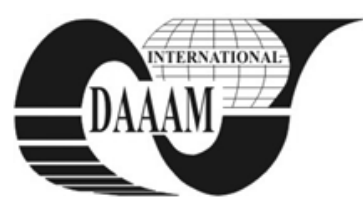

Annals of DAAAM for 2011 \& Proceedings of the 22nd International DAAAM Symposium, Volume 22, No. 1, ISSN 1726-9679 ISBN 978-3-901509-83-4, Editor B. Katalinic, Published by DAAAM International, Vienna, Austria, EU, 2011 Make Harmony between Technology and Nature, and Your Mind will Fly Free as a Bird

Annals \& Proceedings of DAAAM International 2011

\title{
AUTOMATED REHABILITATION DEVICE BASED ON ARTIFICIAL MUSCLES
}

\author{
ZIDEK, K[amil] \& SEMINSKY, J[aroslav]
}

\begin{abstract}
The automated rehabilitation area is currently in fast development together with rehabilitation robotics. This Article is describing design of automated rehabilitation system. The Construction is based on artificial muscle which is much more flexible and safety in limit position than current DC actuated systems. System is primarily designed for upper arm rehabilitation. The load during exercise will be changed by information from integrated sensors. Prediction of rehabilitation progress is handled by neural network. Designed system is simulated and tested in $3 D$ environment with industrial robot platform.
\end{abstract}

Key words: mechatronics, man-machine interactions, neural networks, pneumatic artificial muscle, rehabilitation

\section{INTRODUCTION}

Automated rehabilitation is nowadays in fast development in physical therapy. (Kommu et al., 2007). Automated rehabilitation is a special branch of rehabilitation medicine focused on devices that can be used by people to recover from physical trauma. The first results in this area are described for example in these articles (Pons et al., 2007; Sarakoglou et al., 2007). Within the area of rehabilitation automated machines are more likely to be used. They replace manual procedures by autonomous exercises. There are three main areas of physical therapy: cardiopulmonary, neurological, and musculoskeletal. Though automated rehabilitation has applications in all three areas of physical therapy, most of the work and development is focused on musculoskeletal uses. Musculoskeletal therapy assists in strengthening and restoring functionality in the muscle groups and the skeleton, and in improving coordination. In the current paradigm of physical therapy, many therapists often work with one patient, especially at the early stages of therapy. Automated rehabilitation allows rehabilitation to occur with only one therapist, or none with adequate results. Automated systems allow more consistent training program with automated tracking patient's progress and shifting the stress level accordingly, or making recommendations to the human therapist. In the future automated rehabilitation promises effective results. As the technology develops and prices decrease, rehabilitation systems will be available in everyday life.

\section{CONSTRUCTION PRINCIPLE}

In paper the state-of-art of rehabilitation device for upper arm based on artificial muscles is introduced. Artificial muscles are suitable for these devices because of their flexibility especially in end positions. Presented automated rehabilitation device has three degrees of freedom: 2 DOF in arm and 1 DOF in elbow that provides almost all basic rehabilitation exercises as it was described by (Cuccurullo, 2004). Artificial pneumatics muscles will be tested in connection with spring and antagonistic connection according design (Pitel et al., 2007). This system provides lifting and falling of arm construction.
Possibility to generate help force during rehabilitation or opposite load is there. Artificial muscles are controlled through pneumatic valve terminal from microcomputer based on MCU. The control system at higher level provides artificial intelligence based on neural network for prediction and change of load according sensor values history. Schematic and design of rehabilitation device is displayed in Fig. 3.

The mechanism is fixed to chair for rehabilitation in a comfortable sitting position. Rehabilitation system is designed for both arm (left, right), but not in same time. The patient must change chair for adequate arm.

\section{CONTROL SYSTEM}

The main control part is 8bit MCU (ATMEGA128L microcontroller) that control pneumatics artificial muscle and cooperate with sensors detailed showed in Fig. 1.

The main output part for switching the electromagnetic valves is integrated transistor array, which is directly connected to the microcontroller output. Device is equipped by display and keypad for monitoring of rehabilitation process and practices selection. Microcontroller communicates with a PC by serial link (USART). There is possibility to connect device to mobile PC across USART to USB transducer. The basic control algorithm for the control of the rehabilitation process consists of three parts: (a) Regulatory part, (b) Protective part, (c) User part.

The regulatory part of the algorithm ensures that the rehabilitation device copying required trajectories. An important feature for control of rehabilitation is pressure sensing of arm rehabilitation from limbs. Based on this property we can achieve a suitable speed of shoulder rehabilitation practices in the prescribed mode.

The protective part of the algorithm is designed to ensure safety of the patient during rehabilitation exercises, where for example: in case of detecting of acceleration level over the certain threshold device has to stop the movement of limb within a few milliseconds. The important elements for detection is included acceleration sensor, gyroscope and temperature sensor of human body (to monitor of the muscles during practice).

The user part of the algorithm ensures communication between the user and the microcontroller. By means of eight buttons it is possible to choose several types of rehabilitation practices with various parameters. All data during practice are displayed on the display unit. Since the display that is not able to display all values at once, so individual information rotated cyclically in a time loop (Sun et al., 2007).

\section{NEURAL NETWORK LOAD PREDICTION}

Utilization of artificial intelligence is widely applied in present. There are many experiments with various algorithms, methods and their combination e. g.: neural networks, theory of learning machines (machine learning), fuzzy logic, genetic 
algorithms, experts systems etc. As it was mentioned above the pneumatic artificial muscle is now unused mostly in reason of complicated control because of there is high non-linearity.

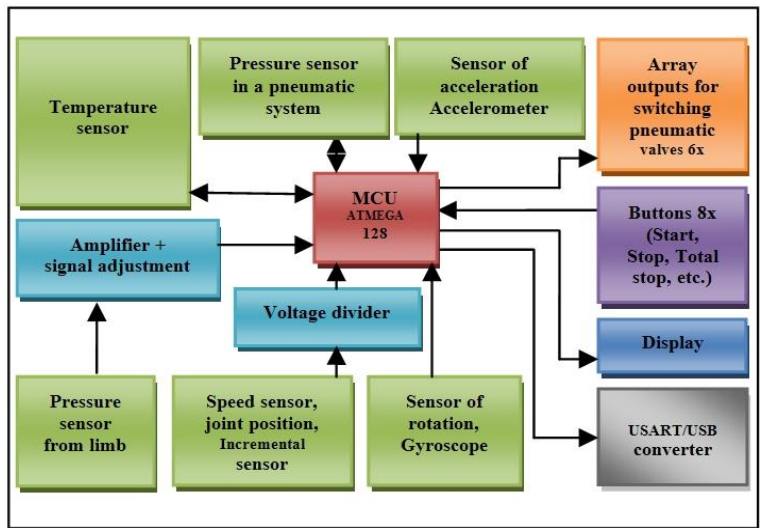

Fig. 1. Principle scheme of control system

Standard types of regulator fail what is main reason of using neural networks. Sequence of operation is visible in the Fig. 2. It describes operation of rehabilitation facility. In diagram is rehabilitation facility represented by operation system.

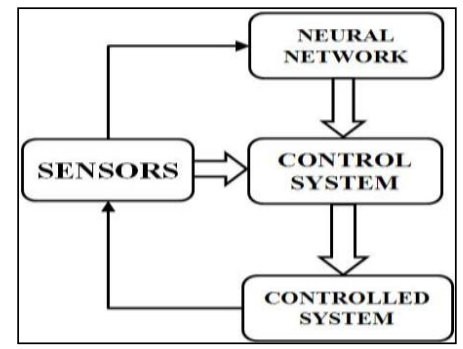

Fig. 2. Control scheme of implementation

In the Fig. 3 neural network is displayed with assigned specific values of four inputs to one output important for correct function NS. There is used NS with back-propagation teaching.

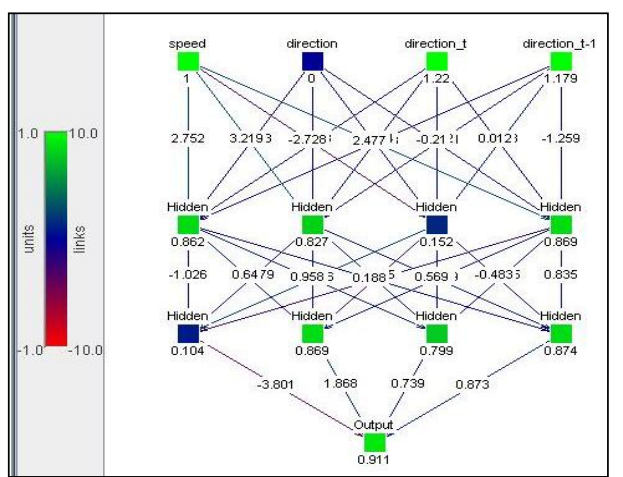

Fig. 3. Neural network for load prediction

\section{TESTING SYSTEM}

Testing platform is based on articulated robot with 5 DOF Mitsubishi RV-2AJ (Hopen \& Hosovsky, 2005). The robot is controlled from external $\mathrm{C \#}$ application through serial port. Rehabilitation device is connected to end of robot efector through flexible coupling. We can reach any position in 3D robot workspace to define testing trajectory easy in drawing area. Testing device can help check safety of rehabilitation device before testing with life patient. Testing device isdisplayed in Fig. 4.

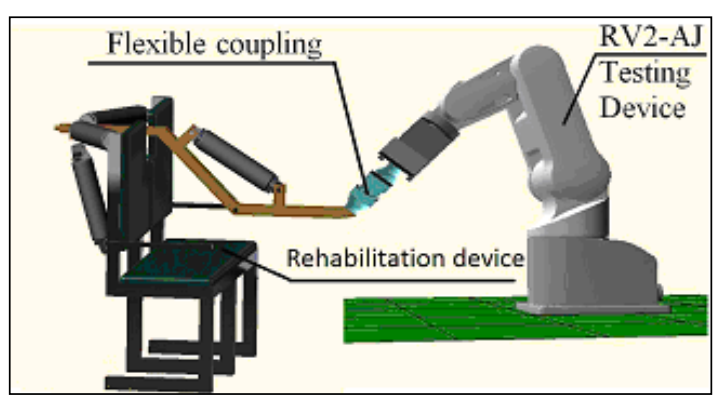

Fig. 4. Simulation of testing device and rehabilitation system

\section{CONCLUSION}

The artificial muscle is using in project as joint actuator because of silent operation and flexibility during movement, start and end position. The goal of developed automated rehabilitation device is to save therapist capacity, to provide improving in prediction of increasing and decreasing load during rehabilitation exercises according patient progress. Prediction of load is based on integrated neural network algorithm. Therefore next step is on base of designed prototype testing system with industrial robot to implement and validate advanced control algorithms of actuator with artificial muscles using methods of artificial intelligence.

\section{ACKNOWLEDGEMENTS}

The research project is supported by the Project of the SF of the EU, Operational Program Research and Development, Measure 2.2 Transfer of knowledge and technology from research and development into practice. Title of the project: Research and development of the intelligent non-conventional actuators based on artificial muscles. ITMS: 26220220103.

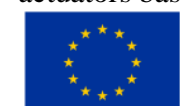

Európska únia

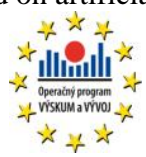

We support research activities in Slovakia / Project is cofinanced from sources of ES

\section{REFERENCES}

Cuccurullo, S. J. (2004). Physical medicine and rehabilitation board review, Demos Medical Publishing, ISBN-10: 1888799-45-5 New York

Hopen, J. M. \& Hosovsky, A. (2005). The servo robustification of the industrial robot, Annals of DAAAM for 2005, 1922nd October 2005, Opatija, ISSN 1726-9679, Katalinic, B. (Ed.), pp. 161-162, DAAAM International, Vienna

Kommu, I. S. et al. (2007). Rehabilitation Robotics, I-Tech Education and Publishing, ISBN 978-3-902613-011 ,Vienna

Pitel, J.; Balara, M. \& Borzikova, J. (2007). Control of the Actuator with Pneumatic Artificial Muscles in Antagonistic Connection. Science Proc. of VSB - TU Ostrava. Vol. 53, No. 2/2007, ISSN 1210-0471 pp. 101-106, Ostrava, CR

Pons, J. L. et al. (2007). Upper-Limb Robotic Rehabilitation Exoskeleton: Tremor Suppression. Rehabilitation Robotics, Sashi S Kommu (Ed.), pp. 453-470, InTech, ISBN 978-3902613-04-2, Opatia

Sarakoglou, I.; et al. (2007). Italy Exoskeleton-Based Exercisers for the Disabilities of the Upper Arm and Hand in Rehabilitation Robotics. Rehabilitation Robotics, Sashi S Kommu (Ed.), pp. 449-522, Itech Education and Publishing, ISBN 978-3-902613-04-2, Vienna

Sun, J., Yu, Y.; Ge, Y. \& Chen, F. (2007). Research on the Multi-Sensors Perceptual System of a Wearable Power Assist Leg Based on CANBUS. Proceedings of the 2007 Int. Conf. on Information Acquisition. ICIA '07. July 9-11, 2007, ISBN 1424412196, pp 132-136, Jeju City, Korea 